\title{
Teaching science concepts relevant to climate change without getting lost in the complexity
}

\section{ROSEMARY HIPKINS}

Teacher question: How does the teaching of climate change and sustainability fit into the teaching of the traditional content and skills of the core science strands? Many students need explicit teaching of core skills and content that slowly builds up their confidence to be successful in specialty senior sciences (Years 12 and 13). Context is there to provide engagement and opportunity for applying learning, but complex context that dominates the narrative of teaching can cause confusion for students with low literacy or poor background knowledge, and can take time away so that teaching of content and skills has to be rushed, which again makes it harder for many students. I love the idea of science teachers being drivers of social change for these issues but I want to teach these topics in a way that doesn't disadvantage students who need us to slowly build up their confidence in core science skills and content. There is always a pull in "environmental issues" topics to go down tangents of politics and society more suited to a social studies classroom, leaving less room for teaching of science skills and content. Any ideas on how to incorporate these ideas without these issues would be amazing! 


\section{Response}

This is a great question! I suspect that many other teachers would share your concerns-and also the assumptions that underpin those concerns. My response is shaped from a perspective that might seem like a bit of a tangent at first. Bear with me because some of the ideas are counterintuitive, but I hope they can help.

I am three-quarters of the way through writing a book called Teaching for Complex Systems Thinking. In a topic such as climate change, there are complex systems galore. The carbon cycle is a complex system. So is the water cycle. And then there's the atmosphere, the ocean, even clouds-all these things are systems, interacting with or embedded in other systems. They are complex because they don't behave in a linear, predictable fashion.

- Their parts can interact in multiple ways.

- Feedback loops can amplify or damp down changes.

- They operate at different levels of scale and changes happen over variable time periods.

- Sometimes a system soaks up stresses and no apparent change happens for ages. But small changes are likely to be accumulating and suddenly the system reaches a tipping point. A big change happens and it can't be reversed easily, if at all. These are called phase changes.

- Sometimes one change triggers another, and that triggers another, and so it goes. These are called cascades of changes.

Just for good measure, human actions can impact these systems in ways we may not fully understand, or be able to readily change. There are so many concepts to digest that it's totally understandable to worry that students just won't get their heads around it all. This is where the research that I have drawn on for the book gets interesting. Here are a few findings that might surprise you.

First, be assured that learning about complexity need not be too hard for students, even if they struggle to easily learn traditional science concepts. According to one big international research group, we are all born to be systems thinkers:

There exists an innate systems intelligence within us all, which begins to unfold from very early childhood on through our universal experiences in family systems and the complex relationships between parents, siblings, peers, and other relatives and caregivers. (Boell \& Senge, 2019, p.6, emphasis in the original).

Children in communities that live close to nature expand this systems intelligence as they are taught to take careful notice of patterns and relationships in their surroundings (Hatcher et al., 2009). Not being in close contact with nature is one of the things that can work against developing our systems intelligence, at least as this applies to the damage our actions are doing to the natural world
(Petersen et al., 2018). The counterintuitive point here is that we need to think carefully about the actual knowledge gap. Is it the (science) concepts that are too hard for students to grasp? Or do we need to pay more careful attention to students' contextual knowledge of the systems that surround and support us, so that their potential for systems thinking can be realised?

Boell and Senge say that the capacity for systems thinking is typically not nurtured at school. (In fact, as I will shortly discuss, some types of learning experiences at school can work against this natural ability.) Another international group has recently reported that using their tools to nurture the habits of complex systems thinkers makes the curriculum more accessible and engaging for all students. Drawing on 20 years of case studies in schools that have been using their tools, they specifically note that special-needs students can experience learning success alongside their peers (The Waters Foundation, n.d.). Partly this engagement and accessibility happens because teaching for complexity uses a lot of visual tools, but there's more going on than just that.

What is it about school learning that can work against our systems-thinking instincts? This question leads to another surprising message from the complex-systems research. The better you are as a teacher at making things simple for students, the more likely it is that you could be working against their ability to think in complexity terms. A leader of one big teacher professional learning initiative in International Baccalaureate Organisation schools explains it like this:

Familiar teaching approaches typically try to reduce complex systems into their parts so they are easier to understand. Then we tend to look for linear cause-andeffect relationships between separate parts. Doing this is problematic because it ignores the essence of the dynamic whole that makes the system what it is. We need to find new ways to keep the wholeness while still making the parts accessible. (Drake et al., 2017, p. 30)

So finding new ways to keep the wholeness of a system is one important message. Drake and her colleagues also mention the importance of not rewarding "quick right answers". Instead students need time to embrace complexity, explore its messiness in familiar contexts, and go with the uncertainties generated by "what if....?" or "it depends whether..." types of questions and explanations. We live with this sort of messiness in our daily lives. The challenge is to bring it into the classroom in a way that still allows students to purposefully build new knowledge and insights. No-one wants to leave them floundering around! That's where the visual tools come into play.

Part-whole thinking involves zooming in and out from the whole system to the details of the parts-inaction. There are lots of ways to build models of whole 
systems-you can even begin with an actual "thing" that stands as a proxy for similar systems in the natural world. For example, one research team working with middle school students began a study of the complexity of aquatic systems with a simple school aquarium and a story about needing to find out why all the fish died (Hmelo-Silver et al., 2017). Another approach is to draw or use a picture of the whole system. Hmelo-Silver and her colleagues recommend using an approach they call CMP (Components, Mechanisms, Phenomena) when describing parts of a system. Once students have learnt to work with these terms they can decide if something is a part (Component) an action that happens in the system (Mechanism) or an event (Phenomenon). Big ideas are more accessible when all these pieces are in play because the learning still resembles recognisable real life experiences.

Some visual tools dig into the dynamics of the mechanisms that drive a system, while still keeping the whole system in view. Stock and flow diagrams are an interesting example. I think they have lots of potential for making complex cycles such as the carbon and water cycles more accessible and engaging. Stocks are things that accumulate and flows are the processes that move those things between stocks. Students can sketch them out on paper like maps. Introductory explanations often use a bathtub model. Here's my quick basic translation to a natural system: the water is a stock, rainfall is an inflow, and the outflow is to a river (Figure 1). Flooding is on my mind as I type this (Napier is in a state of civic emergency).

In Figure 1 I've purposely drawn a fatter arrow going in than coming out-it's very easy to visualise what will happen to the lake level. This super-basic drawing could be expanded in all sorts of different ways, depending on the learning purpose. More inflows or outflows could be added, perhaps to explore the impact of irrigation or hydro power schemes. The context could be changed. You could, for example, start with runoff from city streets and trace where the water accumulates. You get the picture. The basic diagram technique is simple, contexts are integral to the depiction of the systems dynamics, and the possibilities for expanding the model are endless.
A few years ago I had the chance to talk to teachers in an international school in Switzerland who used stock and flow drawings to help upper primary students get their heads around the complexities of migration and refugee flows. One boy, who struggled with literacy and did very little work, got so engaged that he produced more work in this one unit than he had in the whole of the year to date.

Looking back now, I can see that the water-cycle "game" that we developed to support the introduction of key competencies (Figure 2) was almost a stock and flow diagram (Bull et al., 2008). You might have this resource in your school. Six of the circles are places where water collects (yellow=water vapour; magenta=sea water; turquoise=water in living things; pale orange=underground water; mid-blue=fresh water; pink=frozen water). In systems terms they are stocks. The red circle represents a mechanism in systems terms - rain, sleet, snow etc. are types of precipitation. We thought of this circle as a sort of driver at the time, needed to make the game work. The blue and green tracks are flows. We used the colour difference to depict one-way (blue) and reversible (green) flows. This feature created useful learning conversations for students. One teacher who trialled the resource reported higher than usual engagement from her Pasifika students, beginning with figuring out what was going in with the two track colours. Notice also that there is no one right way to get around this system. When compared to typical simplified water cycle diagrams, it is much more contingent and open-ended in its possibilities. It invites question-asking, discussion, and storytelling.

Like other visual tools for systems thinking, stock and flow diagrams can convey accessible ideas for younger students but they can also be used to explore more complex quantitative relationships. This You Tube video ${ }^{1}$ is explicitly set in the context of climate change and explores why reducing emissions somewhat will never be an adequate response-carbon dioxide levels will still keep going up.

You asked about how to ensure that students learn about the human-related aspects of climate change that fall outside your area of expertise. Good question! There is a clear message in the research literature that students need to experience an integrated curriculum because complex

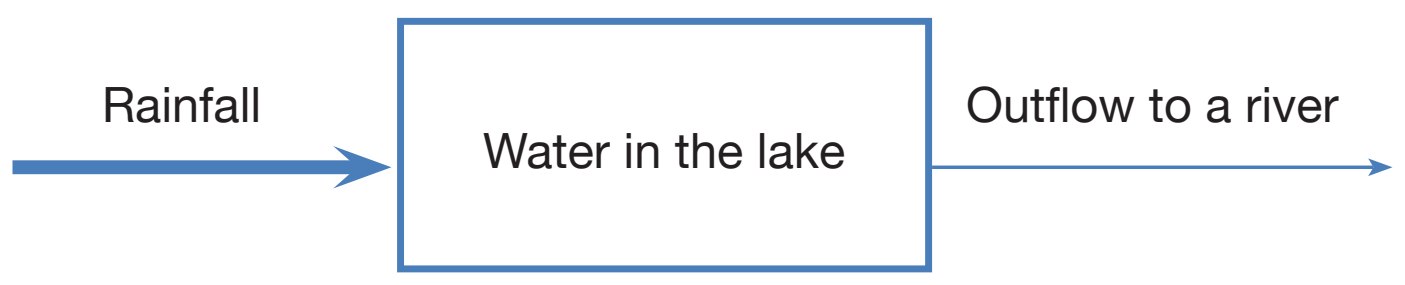

FIGURE 1. A SIMPLE STOCK AND FLOW DIAGRAM 


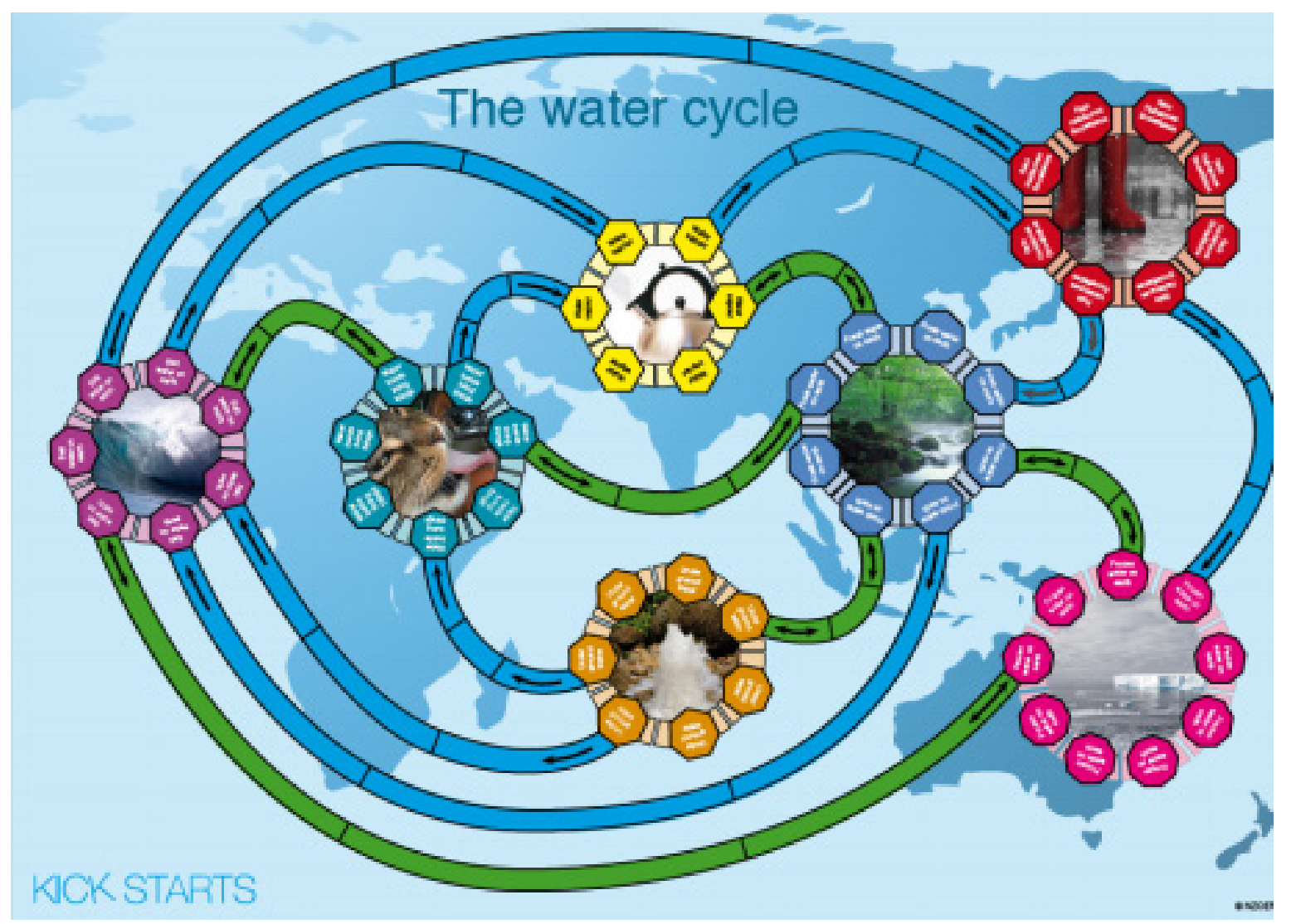

FIGURE 2. THE WATER CYCLE AS A COMPLEX SYSTEM. (SOURCE: BULL ET AL., 2008)

systems are rarely neatly bounded within one subject. However, our own recent research (McDowall \& Hipkins, 2019) suggests it is not easy to design a robust integrated curriculum that keeps the integrity of subjects. This is another area where I think that visual tools can help. If you look at the You Tube clip you'll see that the concept of stocks and flows applies as much to human systems as it does to natural systems. In principle, it should be possible to collaborate with one or more teachers in other learning areas so that students have opportunities to use the same complex systems tools in a range of contexts. Even better would be aligning units so that subjects work in tandem, or sequentially, to develop the topics from a range of subject perspectives.

Stock and flow diagrams are just one of a whole range of visual tools and strategies that can support students to explore complexity without getting lost in detail or bogged down in reading demands. If your students have ready access to e-learning resources, there are many interactive visual models for students of all ages. Science teachers could find the resources of the Concord Consortium2 especially useful. This is an American philanthropic group that makes free resources for schools. There are a number of climate change resources available. Be sure to also check out the Science Learning Hub3 for resources set in a New
Zealand context.

One interesting theme in the research I have been reading is that students need to be able to locate themselves inside the systems they are exploring, not outside them looking in. The learning needs to be grounded in their own place, where they can develop strong connections to the natural systems they are exploring. I've been hearing quite a lot of talk about the need to bring aspects of mātauranga Māori and traditional science together, but I have not seen many practical suggestions about how this could work in schools in ways that keep the integrity of both knowledge systems. It seems to me that there is huge potential in exploring systems from these different knowledge perspectives. Careful attention to patterns and changes in nature is a hallmark of indigenous ways of being in the world, and is also central to complexity research. There are interesting examples in science itself. For example NIWA and the Maniapoto Māori Trust Board have collaboratively developed a framework for monitoring the health of fresh water systems. It was published in August 2020.4 As another example, Rayne et al. (2020) give an interesting account of how they brought both knowledge systems together to address the tricky conservation issue of species translocation. 
This is just a very brief taste of a huge topic. Look out for the book early in 2021. Meanwhile I hope I have been able to provide enough practical ideas that you can dive in and get started. The good news is that many traditional science concepts fit right in to the complexities of climate change. The more challenging news is that the way these topics are taught might need to undergo quite a lot of change.

\section{Acknowledgements}

Thank you for the teacher who posed this question via their Enviroschools facilitator. It's humbling to hear that my draft response is already feeding into professional conversation within the school.

\section{Notes}

I. https://www.youtube.com/watch?v=nRlYGDBGcRA

2. https://concord.org/

3. https://www.sciencelearn.org.nz/topics/climate-change

4. https://niwa.co.nz/sites/niwa.co.nz/files/A5\%20 Maniapoto\%2oCAF_Final_Web.pdf

\section{References}

Boell, M., \& Senge, P. M. (2019). Introduction to the Compassionate Systems Framework in schools. Abdul Latif Jameel World Education Lab, Massachusetts Institute of Technology. https://jwel.mit.edu/sites/mit-jwel/files/assets/ files/intro-compassionatesystemsframework-march-2019_0.pdf

Bull, A., Hipkins, R., Joyce, C., \& MacIntyre, B. (2008). Key competencies: The water cycle, a science journey. New Zealand Council for Educational Research.

Drake, J., Kupers, R., \& Hipkins, R. (2017, Spring/Autumn). Complexity - A big idea for education? IS International School, 19(2), 30-33.
Hatcher, A., Bartlett, C., Marshall, A., \& Marshall, M. (2009). Two-eyed seeing in the classroom environment: Concepts, approaches, and challenges. Canadian Journal of Science, Mathematics and Technology Education, 9(3), 141-153. https:// doi.org/10.1080/14926150903118342

Hmelo-Silver, C. E., Jordan, R., Eberbach, C., \& Sinha, S. (2017). Systems learning with a conceptual representation: A quasi-experimental study. Instructional Science, 45(1), 53-72. https://doi.org/10.1007/s11251-016-9392-y

McDowall, S., \& Hipkins, R. (2019). Curriculum integration: What is happening in New Zealand schools? New Zealand Council for Educational Research. https://www.nzcer.org.nz/ system/files/Curriculum\%20Integration\%202018-2019.pdf

Petersen, J. E., Frantz, C. M., Tincknell, E., \& Canning, C. (2018). An animated visual representation of real-time resource flows through a community enhances systems thinking: Systems thinking is enhanced by animation of community resource flows. Systems Research and Behavioral Science, 35(6), 718-737. https://doi.org/10.1002/sres.2514

Rayne, A., Byrnes, G., Collier-Robinson, L., Hollows, J., McIntosh, A., Ramsden, M., Rupene, M., Tamati-Elliffe, P., Thoms, C., \& Steeves, T. E. (2020). Centring Indigenous knowledge systems to re-imagine conservation translocations. People and Nature, 2(3), 512-526. https://doi.org/10.1002/ pan3.10126

The Waters Foundation. (n.d.). The impact of the Systems Thinking in Schools Project: 20 years of research, development and dissemination. https://waterscenterst.org/wp-content/ uploads/2017/07/STIS_Research.pdf

Rosemary Hipkins is a chief researcher at NZCER.

Email: Rose.Hipkins@nzcer.org.nz 